\title{
Prakiraan Beban Puncak Pada Transformator GITET 150 kV Kesugihan Cilacap Menggunakan Jaringan Syaraf Tiruan Multilayer Feedforward Dengan Algoritma Backpropagation
}

\section{Estimation of Peak Load on GITET $150 \mathrm{kV}$ Transformer in Kesugihan Cilacap Using Multilayer Feedforward Neural Network With Backpropagation Algorithm}

\author{
Dimas Aditia Dicki ${ }^{*}$, Winarso ${ }^{2}$ \\ ${ }^{1,2}$ Program Studi Teknik Elektro, Fakultas Teknik, Universitas Muhammadiyah Purwokerto
}

\section{ARTICLE INFO}

Article history:

DOI:

$\underline{10.30595 / p s p f s . v 1 i .127}$

Submitted:

June 26, 2021

Accepted:

July 12,2021

Published:

Oct 31, 2021

Keywords:

Power transformer, Artificial

Neural Network, Peak Load

\begin{abstract}
The increasing population and the growth of the industrial world, offices, hotels, and modern markets must be directly proportional to Indonesia's availability of electrical energy. The availability of sufficient electrical energy can affect the quality of life of the people and foster investor confidence in our country. Studies on the prediction (estimation) of peak electrical loads in electricity in Indonesia can be carried out using the Artificial Neural Network (ANN) method. The estimation of electricity load for the next 5 years is strongly influenced by several parameters, including population growth and peak load data of $150 \mathrm{kV}$ GITET, Kesugihan Cilacap. This study took population data and peak load data at GITET 150 KV Kesugihan Cilacap in the past 5 years. The data used in this study were actual data, starting from 2015 to 2019. To display the results of the estimated electrical load on the $150 \mathrm{kV}$ GITET transformer, the authors used the artificial neural network method. The peak electrical loads estimation results using artificial neural networks for electricity loads in the next 5 years, to wit from 2020 - 2024. The estimated peak load in Lomanis District is20.0311 MW, 24.443 MW, 19.9707 MW, 19.9705 MW and 19, 9705 MW. In Gombong District, the estimated peak load is 57,398 MW, 57,472 MW, 57,476 MW, 57,474 MW, and 57,479 MW.
\end{abstract}

This work is licensed under a Creative Commons Attribution 4.0 International License.

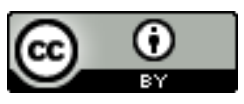

\section{Corresponding Author:}

Dimas Aditia Dicki

Program Studi Teknik Elektro, Fakultas Teknik, Universitas Muhammadiyah Purwokerto

J1 KH. Ahmad Dahlan, PO BOX 202 Purwokerto 53182 Telp. (0281) 636751 ext 130

Email: semnaslppmump2017@gmail.com

\section{PENDAHULUAN}

Semakin meningkatnya jumlah penduduk dan bertumbuhnya dunia industri, perkantoran, perhotelan dan pasar modern harus berbanding lurus dengan ketersediaan energi listrik yang ada di Indonesia. Ketersediaan energi listrik yang cukup dapat mempengaruhi kualitas hidup masyarakat dan menumbuhkan kepercayaan investor di negara kita. Karena dari sisi fungsional energi listrik digunakan sebagai penunjang operasional suatu industri atau badan usaha, sarana publik bahkan rumah tangga. Dalam penyaluran energi listrik dari pusat pembangkit listrik menuju ke pusat beban harus melalui gardu induk (GI) yang mempunyai komponen utama yaitu transformator daya yang berfungsi untuk mentransformasikan daya listrik dengan cara merubah besar tegangan kerja sistem. Kapasitas suatu transformator daya gardu induk perlu diperhatikan dan dipertimbangkan, hal ini bertujuan agar dapat menjangkau kemampuan transformator daya gardu induk dalam memenuhi kebutuhan listrik konsumen PLN harus memiliki perkiraan beban puncak transformator di masa mendatang. Hal ini berguna untuk menjangkau kemampuan transformator dalam beberapa tahun mendatang dan juga PLN dapat melakukan 
antisipasi dini untuk kemungkinan penggantian transformator baru. Oleh karena itu, perlu dilakukan peramalan beban puncak transformator yaitu dengan menggunakan metode Jaringan Syaraf Tiruan ( JST).

JST adalah sebuah alat pemodelan data statistik non-linier. JST dapat digunakan untuk memodelkan hubungan yang kompleks antara input dan output untuk menemukan pola-pola pada data.. Peramalan merupakan proses untuk memperkirakan kejadian/hal pada masa yang akan datang, peramalan memerlukan data historis dan memproyeksikannya ke masa depan dengan beberapa model matematis\{7]. Peramalan beban transformator dapat dikategorikan sebagai peramalan kuantitatif. Peramalan kuantitatif ini dapat diterapkan jika tersedia informasi tentang masa lalu, Informasi tersebut dapat dikuantitatifkan dalam bentuk data numerik dan dapat diasumsikan bahwa beberapa aspek pola masa lalu akan terus berlanjut di masa yang akan datang [2]. Peramalan beban sangat membantu perusahaan listrik dalam mengambil keputusan untuk menyuplai tenaga listrik termasuk keputusan dalam mengatur pembangkitan, pemutusan beban (load switching), dan juga pembangunan infrastruktur Peramalan beban listrik (load forecast) atau kebutuhan listrik (demand forecast) merupakan langkah awal dari Rencana Usaha Penyediaan Tenaga Listrik (RUPTL). Pada tahun 2014, Sesa, Suyono, Hasanah, [5] melakukan penelitian peramalan beban listrik dengan metode JST di kota Ambon, hasil peramalan permintaan beban listrik mengalami peningkatan sebesar 88,233 MW. Pada tahun yang sama yaitu 2014, Nurkholiq, Sukmadi, Nugroho [4] melakukan penelitian untuk masa peramalan (2013-2022) yang diperoleh dari hasil trenline kemudian disimulasikan ke JST, dengan Kesimpulan hasil peramalan dengan JST, konsumsi energi listrik mengalami kenaikan yaitu dari 173.990 Gwh pada tahun 2012 menjadi sebesar 242.120 pada tahun 2022, terjadipeningkatan konsumsi energi listrik sebesar 68.130 Gwh. Kemudian p ada tahun 2018 Syahfitra, [6] meneliti beban puncak transfromator daya di Gardu Induk Bumiayu untuk waktu prediksi selama 10 tahun dengan menggunakan metode JST. Hasil prediksi beban puncak trasfromator mengalami kenaikan yang masih wajar. Dari penelitian terdahulu, dapat dikaji bahwa peramalan beban puncak menggunakan metode jaringan syaraf tiruan menjadi jawaban yang tepat, dengan hasil yang begitu baik. Berdasarkan latar belakang yang telah dipaparkan diatas, maka penulis mengambil judul penelitin "Prakiraan Beban Puncak Pada Transformator GITET 150 kV Kesugihan Cilacap Menggunakan Jaringan Syaraf Tiruan Multilayer Feedforward Dengan Algoritma Backpropagation".

\section{METODE PENELITIAN}

Dalam pembuatan sistem peramalan beban listrik menggunakan jaringan syaraf tiruan ini penulis memerlukan alat serta komponen-komponen yang mendukung terciptanya sistem yang diinginkan seperti personal computer dan software MATLAB 2017. Agar peneltian ini efektif dan efisien maka semua kegiatan harus terjadwal sesuai dengan waktu yang telah ditentukan yaitu dimulai dengan studi literature,membuat diagram alir proses, pengumpulan data primer dari PT.PLN yaitu data historis beban puncak trafo dan data kependudukan kabupaten cilacap, kemudian menginput data, simulasi jaringan syaraf tiruan, peramalan beban listrik dan diakhiri dengan menampilkan hasil beban peramalan, alur penelitian dilihat pada gambar 1: 


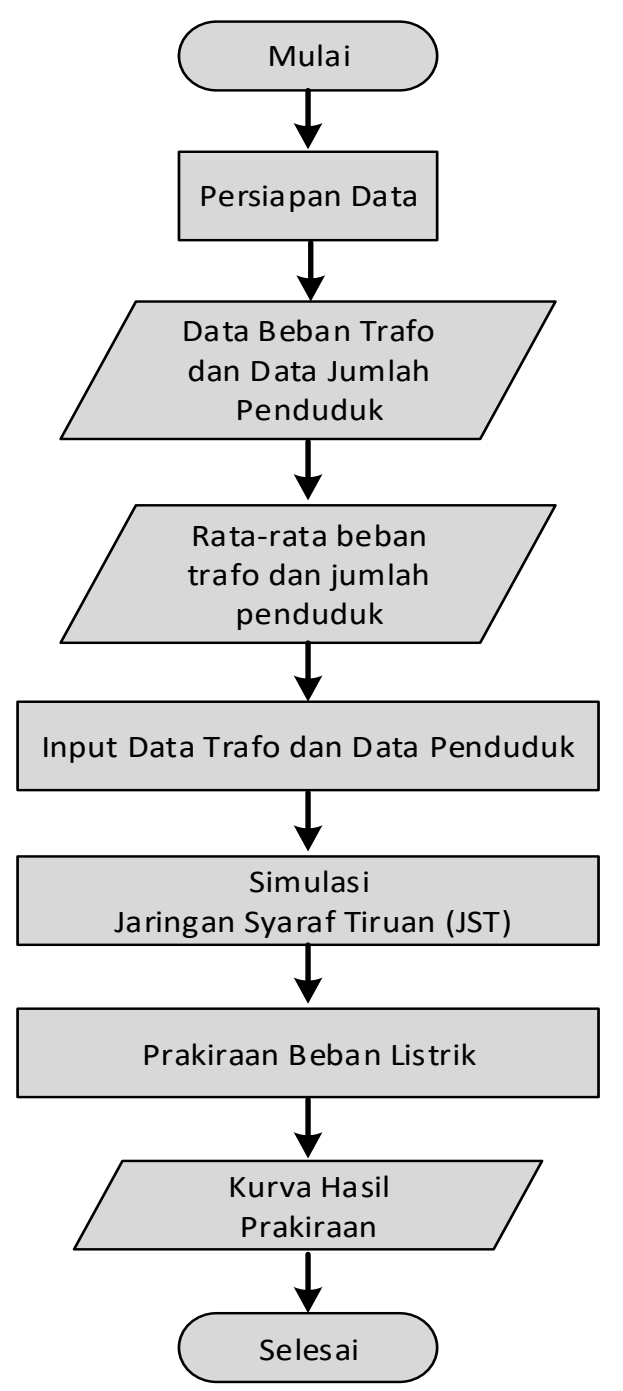

Gambar 1. Alur Penelitian

\section{HASIL DAN PEMBAHASAN}

\section{Model Jaringan}

Jaringan yang dibentuk pada penelitian ini merupakan jaringan multilayer yang terdiri dari

1 lapisan input, 2 lapisan tersembunyi dan 1 lapisan output. Dengan jumlah neuron pada masing- masing lapisan tersembunyi adalah 30 neuron pada lapisan tersembunyi pertama, dan 10 neuron pada lapisan tersembunyi kedua.

A. Penentuan Data Input, Variabel input jaringan terdiri dari :

$\mathrm{X} 1$ adalah jumlah penduduk, $\mathrm{X} 2$ adalah data beban trafo dan $\mathrm{Y}$ adalah rata-rata

B. Data Input

Tabel 1 Data Input Trafo $150 \mathrm{kV}$ GITET Kesugihan konsumen Lomanis

\begin{tabular}{rrrrrr}
\hline Tahun & 2015 & 2016 & 2017 & 2018 & 2019 \\
\hline X1 & 9.622 & 10.089 & 5.196 & 5.447 & 5.478 \\
X2 & 30.439 & 37.819 & 30.798 & 37.016 & 35.396 \\
Y & 20.0305 & 23.954 & 17.997 & 21.2315 & 20.437
\end{tabular}


Tabel 2 Data Input Trafo 150 kV GITET Kesugihan konsumen Gombong

\begin{tabular}{rrrrrr}
\hline Tahun & 2015 & 2016 & 2017 & 2018 & 2019 \\
\hline X1 & 50.018 & 50.993 & 50.881 & 51.071 & 51.336 \\
X2 & 41.580 & 46.397 & 41.795 & 73.665 & 51.205 \\
Y & 45.799 & 48.695 & 46.338 & 62.368 & 51.2705 \\
\hline
\end{tabular}

\section{Hasil Peramalan Beban Puncak menggunakan JST}

Setelah melakukan pelatihan pemasukan data dilanjutkan dengan tahap berikutnya yaitu prakiraan atau prediksi, dalam tahap ini dilakukan prakiraan untuk 5 tahun mendatang yaitu sampai dengan tahun 2024.

\section{Hasil Training Peramalan Beban Puncak GITET 150 kV Kesugihan Konsumen Lomanis}

Pada tabel 3 merupakan hasil peramalan beban puncak dengan input dan target beserta hasil didalamnya, sedangkan gambar 2 adalah grafik peramalan beban puncak selama 5 tahun kedepan.

Tabel 3 Hasil Peramalan Jaringan Syaraf Tiruan untuk Lomanis

\begin{tabular}{ccccc}
\hline Tahun & X1 & $\begin{array}{c}\text { X2 } \\
(\mathrm{MW})\end{array}$ & $\begin{array}{c}\text { X3 } \\
(\mathrm{MW})\end{array}$ & $\begin{array}{c}\text { Hasil Peramalan } \\
\text { JST (MW) }\end{array}$ \\
\hline 2020 & 9,622 & 30,439 & 20,030 & 20,0311 \\
2021 & 10,08 & 37,819 & 23,954 & 24,443 \\
2022 & 5,196 & 30,798 & 17,997 & 19,9707 \\
2023 & 5,447 & 37,016 & 21,231 & 19,9705 \\
2024 & 5,478 & 35,396 & 20,437 & 19,9705 \\
\hline
\end{tabular}

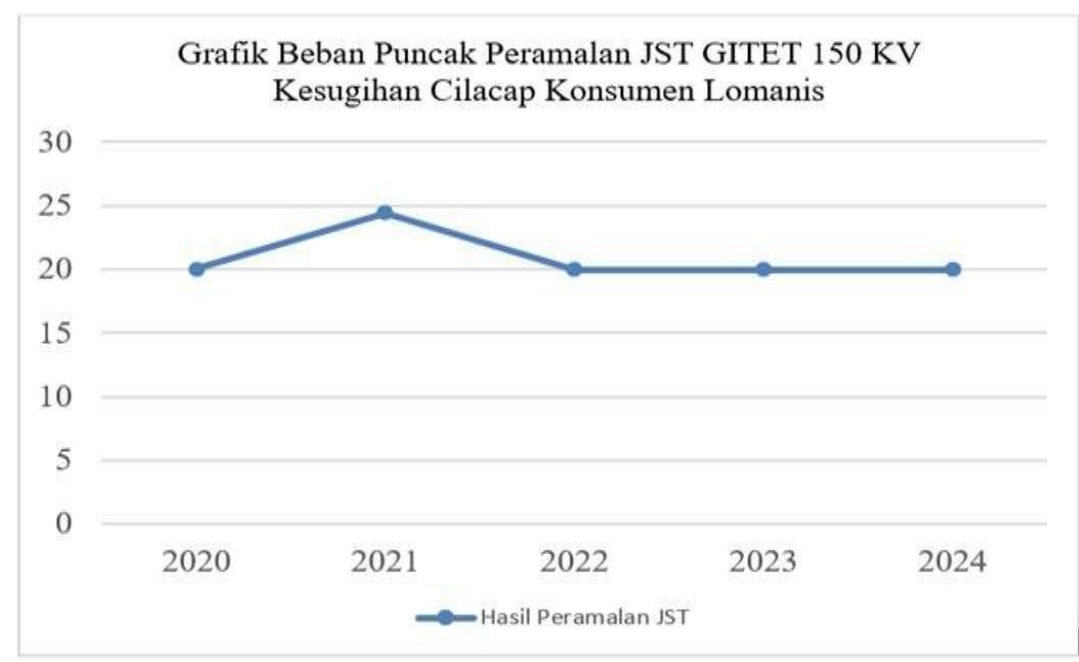

Gambar 2. Grafik hasil peramalan JST

Berdasarkan hasil prediksi yang ditunjukkan pada Tabel 3 dan Gambar 1 bahwa beban puncak transformator sempat mengalami kenaikan pada tahun 2020 dan 2021. Namun mulai tahun 2022 dan seterusnya, beban puncak transformator terus mengalami tren penurunan setiap tahunnya. Hal ini berbanding lurus dengan data penduduk yang mengalami penurunan. Pada tahun 2024, beban puncak transformator memperoleh hasil prediksi sebesar 19,97 MW. 
Hasil Training Peramalan Beban Puncak GITET 150 KV Kesugihan Konsumen Gombong

Pada tabel 4 merupakan hasil peramalan beban puncak dengan input dan target beserta hasil didalamnya, sedangkan gambar 3 adalah grafik peramalan beban puncak selama 5 tahun kedepan.

Tabel 4. Hasil Peramalan Jaringan Syaraf Tiruan untuk Kesugihan Konsumen Gombong

\begin{tabular}{lrllc} 
TAHUN & X1 & X2 (MW) & X3 (MW) & Hasil Peramalan JST (MW) \\
& & & & \\
\hline 2020 & 50,018 & 41,580 & 45,799 & 57,398 \\
2021 & 50,993 & 46,397 & 48,695 & 57,472 \\
2022 & 50,881 & 41,795 & 46,338 & 57,476 \\
2023 & 51,071 & 73,665 & 62,368 & 57,474 \\
2024 & 51,336 & 51,205 & 51,2705 & 57,479 \\
\hline
\end{tabular}

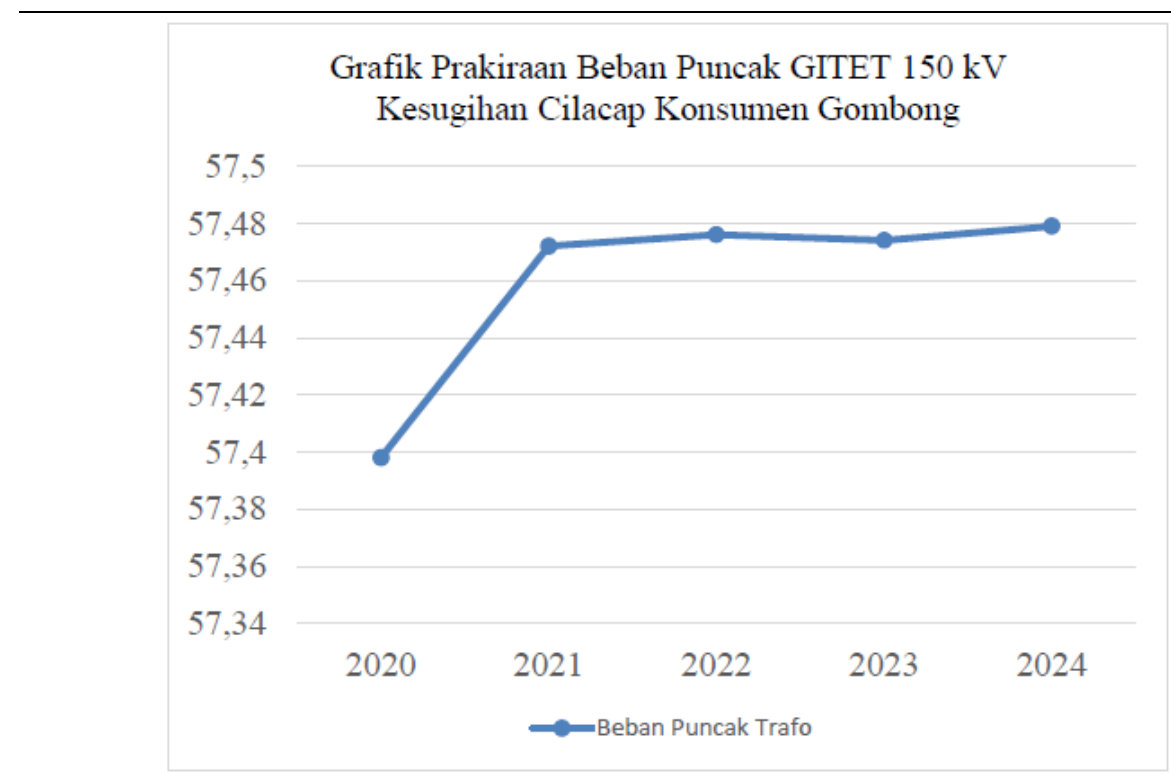

Gambar 3. Grafik hasil peramalan JST

Dari informasi pada Tabel 4 dan Gambar 3, menunjukkan bahwa hasil prediksi beban puncak transformator mengalami tren naik turun setiap tahunnya.Hal ini berbanding lurus dengan bertambah dan turunnya nilai PDRB dan jumlah penduduk yang dilayani transformator. Pada tahun 2024, prediksi bebanpuncak transformator yang dihasilkan adalah 57,479 MW.

\section{Peramalan Beban Puncak Menggunakan Metode Regresi Linier}

\section{Peramalan Beban Puncak Pada Konsumen Lomanis}

Dari data transformator dan penduduk Lomanis yang diperoleh dari tahun 2015 sampai dengan tahun 2019 dapat dilakukan analisis regresi linear untuk menentukan nilai konstanta "a" dan koefisien regresi b, kemudian dapat dihitung untuk menentukan variabel y dan lainnya seperti pada tabel 5 dan tabel 6 . 
Tabel 5. Perhitungan untuk mendapatkan Konstanta a dan Koefisien Regresi b beban puncak transformator konsumen Lomanis

\begin{tabular}{ccccc}
\hline Tahun & $\begin{array}{c}\text { Variabel x: } \\
\text { Periode } \\
\text { Tahun }\end{array}$ & $\begin{array}{c}\text { Variabel y: Beban } \\
\text { Transformator } \\
(\mathrm{MW})\end{array}$ & $\mathrm{X}^{2}$ & $\mathrm{X.Y}$ \\
\hline 2015 & 1 & 20,0305 & 1 & 20,0305 \\
2016 & 2 & 23,954 & 4 & 47,908 \\
2017 & 3 & 17,997 & 9 & 53,991 \\
2018 & 4 & 21,2315 & 16 & 84,926 \\
2019 & 5 & 20,437 & 25 & 102,185 \\
TOTAL & 15 & 103,65 & 55 & 309,0405 \\
\hline
\end{tabular}

Tabel 6. Hasil Prediksi Jumlah beban puncak GITET Kesugihan Cilacap pada konsumen Lomanis menggunakan metode Regresi linier

\begin{tabular}{cccccc}
\hline Tahun & \multicolumn{1}{c}{$\mathrm{y}$} & & & $\mathrm{y}^{\prime}=\mathrm{a}+\mathrm{bx}$ \\
& $\mathrm{X}$ & $(\mathrm{MW})$ & $\mathrm{X}^{2}$ & $\mathrm{X} . \mathrm{Y}$ & $(\mathrm{MW})$ \\
\hline 2020 & 1 & 20,0305 & 1 & 20,031 & 21,112 \\
2021 & 2 & 23,954 & 4 & 47,908 & 20,921 \\
2022 & 3 & 17,997 & 9 & 53,991 & 20,730 \\
2023 & 4 & 21,2315 & 16 & 84,926 & 20,539 \\
2024 & 5 & 20,437 & 25 & 102,185 & 20,348 \\
\hline
\end{tabular}

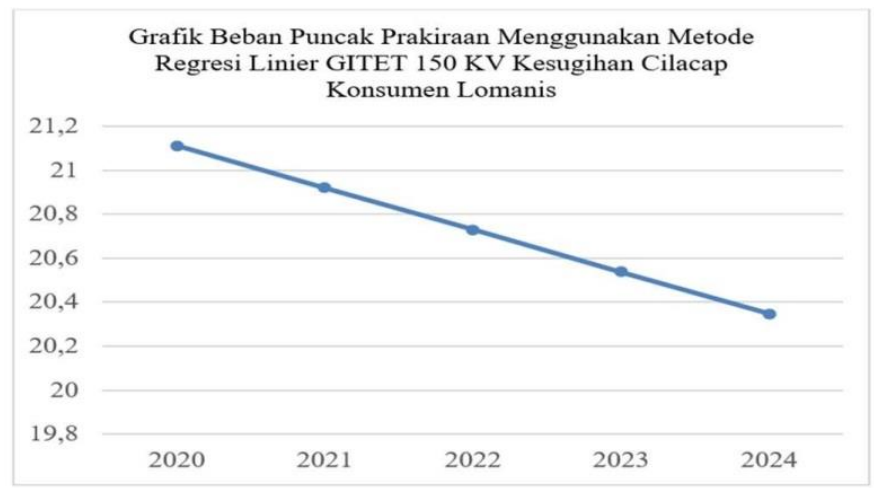

Gambar 4. Grafik Beban Puncak Hasil Regresi Linier

Berdasarkan hasil prediksi yang ditunjukkan pada Tabel 6 dan Gambar 4, bahwa beban puncak transformator sempat mengalami kenaikan pada tahun 2020. Namun mulai tahun 2021 dan seterusnya, beban puncak transformatorterus mengalami tren penurunan setiap tahunnya. Hal ini berbanding lurus dengan data penduduk yang mengalami penurunan. Pada tahun 2024, beban puncak transformator mempreoleh hasil prediksi sebesar 20,34 MW.

\section{Peramalan Beban Puncak Transformator Pada Konsumen Gombong}

Rekapitulasi data transformator dan penduduk Gombong yang diperoleh dari statistik perusahaan mulai tahun 2015 sampai dengan tahun 2019 dapat dilakukan analisis regresi linear untuk menentukan nilai konstanta a dan koefisien regresi b, kemudian dapat dihitung untuk menentukan variabel y dan lainnya seperti pada tabel 7 dan tabel 8. 
Tabel 7. Hasil Prediksi Jumlah beban puncak GITET Kesugihan Cilacap pada konsumen Gombong

\begin{tabular}{ccccc}
\hline Tahun & $\begin{array}{c}\text { Variabel x: Periode } \\
\text { Tahun }\end{array}$ & $\begin{array}{c}\text { Variabel y: Beban } \\
\text { Transformator (MW) }\end{array}$ & $\mathrm{X}^{2}$ & X.Y \\
\hline 2015 & 1 & 45,799 & 1 & 45,799 \\
2016 & 2 & 48,695 & 4 & 97,39 \\
2017 & 3 & 46,338 & 9 & 139,014 \\
2018 & 4 & 62,368 & 16 & 249,472 \\
2019 & 5 & 51,2705 & 25 & 256,3525 \\
TOTAL & 15 & 254,4705 & 55 & 788,0275 \\
\hline
\end{tabular}

Tabel 8. Hasil Prediksi Jumlah beban puncak GITET Kesugihan Cilacap pada konsumen Gombong

\begin{tabular}{cccccc}
\hline Tahun & $\mathrm{X}$ & $\begin{array}{r}\mathrm{y} \\
(\mathrm{MW})\end{array}$ & $\mathrm{X}^{2}$ & $\mathrm{c}$ & \multicolumn{2}{c}{$\mathrm{y}^{\prime}=\mathrm{a}+\mathrm{bx}$} \\
& 1 & 45,799 & 1 & 45,799 & 45,971 \\
2020 & 2 & 48,695 & 4 & 97,39 & 48,433 \\
2021 & 3 & 46,338 & 9 & 139,014 & 50,894 \\
2022 & 4 & 62,368 & 16 & 249,472 & 53,356 \\
2023 & 5 & 51,2705 & 25 & 256,3525 & 55,817 \\
2024 & & & & &
\end{tabular}

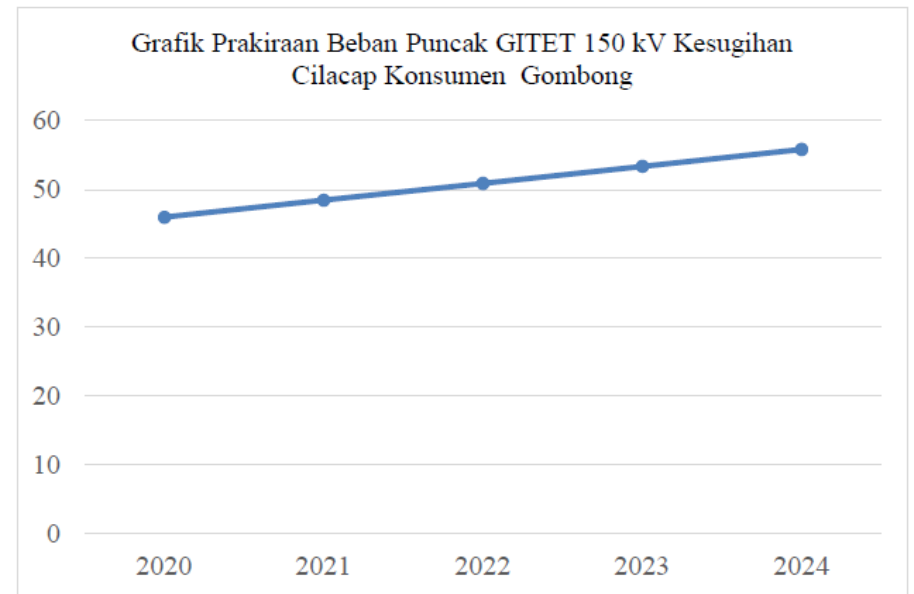

Gambar 5. Grafik Grafik Beban Puncak Hasil Regresi Linier

Dapat dilihat pada Tabel 8 dan Gambar 5 yang menunjukkan bahwa hasil prediksi beban puncak transformator mengalami tren naik turun setiap tahunnya. Hal ini berbanding lurus dengan bertambah dan turunnya nilai PDRB dan jumlah penduduk yang dilayani transformator. Pada tahun 2024, prediksi beban puncak transformator yang dihasilkan adalah 55,81 MW.

\section{Perbandingan peramalan beban puncak menggunakan jaringan syaraf tiruan backpropagation dengan} metode regresi linier

Hasil penelitian, analisis, hingga pengujian sistem perbandingan metode jaringan syaraf tiruan backpropagation dan metode regresi linier pada peramalan beban puncak ini, didapatkan kesimpulan sebagai berikut:

a. Metode jaringan syaraf tiruan backpropagation dan metode regresi linier dapat digunakan untuk peramalan beban puncak transformator. 
b. Tingkat kecocokan hasil peramalan beban puncak tergantung pada kombinasi nilai parameter yang digunakan dalam proses pembelajarannya. Dari hasil pengujian,maka didapatkan kombinasi parameter terbaik dari metode jaringan syaraf tiruan backpropagation yaitu maksimal perulangan 10,rasio pembelajaran 0,1 dan minimal error 0,1 . Sedangkan parameter terbaik dari metode regresi linier yaitu maksimal perulangan 50, rasio pembelajaran 0,5 dan minimal error 0,001 .

c. Hasil pengujian, didapatkan hasil peramalan beban puncak listrik menggunakan jaringan syaraf tiruan untuk beban listrik 5 tahun kedepan, yaitu dari tahun 2020 - 2024 dengan hasil sebagai berikut: peramalan beban puncak pada Kecamatan Lomanis adalah 20,0311 MW, 24,443 MW, 19,9707 MW, 19,9705 MW, dan 19,9705 MW. Dan pada Kecamatan Gombong peramalan beban puncaknya adalah 57,398 MW, 57,472 MW, 57,476 MW, 57,474 MW, dan 57,479 MW.

d. Hasil peramalan beban puncak listrik menggunakan metode regresi linier untuk beban listrik 5 tahun kedepan, yaitu dari tahun 2020 - 2024 dengan hasil sebagai berikut: peramalan beban puncak pada Kecamatan Lomanis adalah 21,11 MW, 20,92 MW, 20,73 MW, 20,53 MW, dan 20,34 MW. Dan pada Kecamatan Gombong peramalan beban puncaknya adalah 45,97 MW, 48,53 MW, 50,89 MW, 53,35 MW, dan 55,81 MW.

\section{KESIMPULAN}

Berdasarkan hasil penelitian peramalan beban puncak pada transformator GITET $150 \mathrm{kV}$ Kesugihan menggunakan jaringan syaraf tiruan multilayer feedforwad menggunakan algoritma backpropagation, dapat ditarik kesimpulan:

a. Peramalan beban puncak transformator menggunakan jaringan syaraf tiruan, pada konsumen Lomanis dari tahun 2019 sampai tahun 2024 mengalami tren naik turun setiaptahunnya. Pada tahun 2020, peramalan beban puncak yang akan dihasilkan adalah sebesar 20,03 MW, tahun 2021 peramalan beban puncak mengalami kenaikan menjadi 24,443 dan pada tahun 2024 peramalan beban puncak yang dihasilkan mengalami tren penurunan sebesar 57,49 MW. Hal ini berbanding lurus dengan naik turunnya jumlah penduduk yang berakibat pada beban daya yang akan dihasilkan.

b. Peramalan beban puncak transformator menggunakan jaringan syaraf tiruan, untuk konsumen Gombong dari tahun 2019 sampai tahun 2024 mengalami tren naik turun pada setiap tahunnya. Pada tahun 2020, peramalan beban puncak yang akan dihasilkan adalah sebesar 57,39 MW dan tahun 2024 peramalan beban puncak yang akan dihasilkan adalah sebesar 57,49 MW. Hal ini berbanding lurus dengan naik turunnya jumlah penduduk yang berakibat pada beban daya yang akan dihasilkan.

c. Peramalan beban puncak menggunakan metode regresi linier pada konsumen Lomanis mengalami tren naik turun, seperti halnya hasil peramalan mengunakan metode jaringan syaraf tiruan. Dimana hasil dari metode regresi linier itu sendiri pada peramalan tahun 2020 dan 2021 mengalami kenaikan beban puncak sebesar 21,11 MW dan 20,92 MW. Lalu untuk tahun 2022 sampai tahun 2024 mengalami tren penurunan dengan hasil perkiraan beban puncak 20,73 hingga 20,34. Hal ini berbanding lurus dengan data kependudukan penduduk Kecamatan Lomanis yang juga mengalami tren naik turun pada setiap tahunnya.

d. Hasil peramalan beban puncak menggunakan metode regresi linier untuk Gombong, mengalami hasil perkiraan turun naik. Pada perkiraan tahun 2020 hasil beban puncak sebesar 45,97 MW, naik kembali pada tahun 2021 sampai tahun 2024, dimana hasil peramalan tersebut sebesar 48,43 sampai 55,81 MW.

\section{DAFTAR PUSTAKA}

\section{Cilacap, G. K. (2015-2019). Data Beban Trafo. Cilacap: GITET 150 kV Kesugihan Cilacap}

Handayani, I., Alimudin, \& Suhendar. (2012). Peramalan Beban Tenaga Listrik Jangka Pendek menggunakan Metode Jaringan Syaraf Tiruan.Kabupaten Cilacap, D. D., \& Kabupaten Kebumen, D. D. (20152019).

Data Kependudukan Lomanis dan Gombong . : Dinas Kependudukan dan Catatan Sipil Kabuaten Cilacap dan Kebumen.

Nurkholiq, N., Sukmadi, T., \& Nugroho , A. (2014). Analisis Perbandingan Metode Logika Fuzzy Dengan Jaringan Syaraf Tiruan Backpropagation Pada Peramalan Kebutuhan Energi Listrik Jangka Panjang di Indonesia Sampai Tahun 2022.

Sesa, S., Suyono, H., \& Khasanah, N. R. (2014). Peramalan Beban Listrik Jangka Menengah Menggunakan Jaringan Syaraf Tiruan Pada Sistem Kelistrikan Kota Ambon. Journal Articel, 19-25. 
Syahfitra, F. D. (2018). Penerapan Jaringan Syaraf Tiruan Backpropagation Sebagai Sistem PeramalanBeban Puncak Transformator Gardu Induk Bumiayu. journal article, 1-10

Triwulan, Y., Hariyanto, N., \& Anwari, S. (2013). Peramalan Beban Listrik Jangka Pendek Menggunakan Metode Jaringan Syaraf Tiruan. Journal Article, 4. 